\title{
Self-medication in animals: new approach for the future studies
}

\section{Opinion}

Our first medicine is our food. The consumption of food plants by animals in the wild suggests two aims as needs in bioenergetics and a possible self-medication. However, many studies led across Africa on primates have already reported this self-medication behavior such as. ${ }^{1,2}$ Therefore, there are different criteria for different cases $^{3}$ among which:

1) Evidence the animal sick,

2) Ingests something that is not part of the normal diet,

3) The ingested plant has known properties to counter that sickness,

4) Demonstrated presence of active compounds in the plant that treat or relieve symptoms (this does not apply for leaf swallowing or geophagy). In the case of leaf swallowing, the evidence is in the presence of worm in the feces.

5) Demonstrated that the animal recovered from the illness as a result of ingestion of said medicinal plants or soil, whole leaves.

In the present manuscript I will focus of assumption (4) describe upper concerning the leaf swallowing.

I. The leaf species swallowed found in the feces, whole and or partially chewed, could also be assimilated to an amount of energy that is not transformed by the organism (cell). The evidence that this can only attributed to self-medication behavior could be debatable.

II. I think that the mechanical effect of rough leaves is sometimes not very obvious or sufficient to explain by itself the expulsion of the intestinal worms, which can also be due to a high parasitaemia because of which the worms also come out of themselves due to the intestine movements as in the young individuals without any particular ingestion. It would be necessary also to consider the chemical effect of the pharmacological substances contained in these leaves, especially in case these plants have medicinal value for local people too. ${ }^{4}$

As a result, this interpretation of animal behavior could be a source of anthropomorphism as pointed out by Poirier-Poulin. ${ }^{5}$ Several literatures do not support the idea that the chemical properties of plants would be responsible for the expulsion of parasites for i.e. Huffman $\&$ Caton. ${ }^{6}$ For the future study I suggest to establish the relationship between pharmacological properties contained in the leaf species to expulse of intestinal worms.

\section{Acknowledgement}

I would like to thank Michael Huffman and Caroline Chesnoy for our fruitful discussions. My grateful also goes to Rebecca Miller for the invitation to submit this manuscript.

\author{
Volume 8 Issue 2 - 2018 \\ Ulrich Maloueki, ${ }^{1,2}$ \\ 'University of Kinshasa, Faculty of Science, Department of \\ Biology, Democratic Republic of the Congo \\ ${ }^{2}$ Odzala-Kokoua Foundation, African Parks, Republic of Congo
}

Correspondence: Ulrich Maloueki, University of Kinshasa, Faculty of Science, Department of Biology, PO. Box Kinshasa XI, Kinshasa, Democratic Republic of the Congo, Tel +242 05566 38 02; Email maloueki.ulrich@gmail.com

Received: February 20, 2018| Published: March 15, 2018

\section{Conflict of interest}

I certify there is no conflict of interest with any organization concerning the writing of this manuscript because this work has received no financial support.

\section{References}

1. Huffman MA. The C.H.I.M.P.P. Group: A Multi-disciplinary Investigation into the Use of Medicinal Plants by Chimpanzees. Pan African News. 1994;1(1).

2. Fruth B, Ikombe BN, Matshimba KG, et al. New Evidence for SelfMedication in Bonobos: Manniophytonfulvum Leaf- and StemstripSwallowing From Luikotale, Salonga National Park, DR Congo. Am J Primatol. 2014;76(2):146-158.

3. Huffman MA. Current Evidence for Self-Medication in Primates: A Multidisciplinary Perspective. Yearbook of Physical Anthropology.1997;40:171-200.

4. Maloueki U, Lutonadio MLS, Ndimbo KSP, et al. Propriétés ethnomédicinales et pharmacologiques des plantes consommées par les bonobos (Pan Paniscus) à Bolobo, République Démocratique du Congo: Végétation Herbacée Terrestre. Ethnopharmacologia. 2015;54:60-73.

5. Poirier-Poulin S. Les primates non humains sont-ils médecins? Une analyse critique des études sur l'automédication et de ses mécanismes premiers, 2016.

6. Huffman MA, Caton JM . Self-induced Increase of Gut Motility and the Control of Parasitic Infections in Wild Chimpanzees. International Journal of Primatology. 2001;22(3):329-346. 